\title{
MIDAS
}

Museus e estudos interdisciplinares

6 | 2016

Dossier temático: "Museus, discurso e poder"

\section{O Museu Nacional de Arte Contemporânea sob a direção de Eduardo Malta}

The National Museum of Contemporary Art under the direction of Eduardo Malta

\section{Rita Duro}

\section{OpenEdition}

\section{Journals}

\section{Edição electrónica}

URL: http://journals.openedition.org/midas/1002

DOI: $10.4000 /$ midas. 1002

ISSN: 2182-9543

\section{Editora:}

Alice Semedo, Paulo Simões Rodrigues, Pedro Casaleiro, Raquel Henriques da Silva, Ana Carvalho

\section{Refêrencia eletrónica}

Rita Duro, «O Museu Nacional de Arte Contemporânea sob a direção de Eduardo Malta », MIDAS

[Online], 6 | 2016, posto online no dia 04 abril 2016, consultado no dia 03 maio 2019. URL : http:// journals.openedition.org/midas/1002 ; DOI : 10.4000/midas.1002

Este documento foi criado de forma automática no dia 3 Maio 2019.

\section{c) (i) (2)}

Midas is licensed under a Creative Commons Attribution-NonCommercial-ShareAlike 3.0 International License 


\section{O Museu Nacional de Arte Contemporânea sob a direção de Eduardo Malta}

The National Museum of Contemporary Art under the direction of Eduardo Malta

\section{Rita Duro}

\section{NOTA DO EDITOR}

Artigo recebido a 31.03.2015

Aprovado para publicação a 18.12.2015

\section{Introdução}

1 O presente artigo centra-se na ação do pintor Eduardo Malta (1900-1967) enquanto diretor no Museu Nacional de Arte Contemporânea (MNAC), entre 1959 e 1967. Com base na pesquisa realizada e recorrendo à consulta de documentação inédita, privilegiamos neste artigo uma análise que enquadra e apresenta os primeiros anos de Malta como pintor até à sua nomeação para diretor do MNAC. ${ }^{1}$ Nesse campo, analisamos a sua administração através de episódios significativos nas áreas específicas das aquisições, exposições (permanente e temporárias), catálogos publicados e a relação com os públicos. Pretende-se, ainda, entender o lugar que a direção de Malta ocupou no panorama museológico português dos anos de 1960, caraterizado por uma tímida mudança ${ }^{2}$, em que a ação, discurso e política do Estado Novo se encontravam debilitados comparativamente ao período de António Ferro (1895-1956), e, em paralelo, pelo surgimento de uma progressiva abertura à política alternativa de cariz privado ${ }^{3}$. 
A nomeação prova mais um vez o desacerto entre a cultura e o Regime; está em contradição flagrante com as repetidas invocações dos novos iniciados num discurso histórico do Sr. Presidente do Conselho [...]. ${ }^{4}$

2 Neste excerto de maio de 1959, Júlio Pomar manifesta o seu desagrado relativamente à nomeação do pintor para diretor do MNAC. $\mathrm{O}$ acontecimento marcou profundamente a história do museu e o panorama artístico português da época, revelando a clara intenção de estrangulamento e controlo, por parte do Estado Novo, do discurso sobre a arte contemporânea e dos respetivos organismos museológicos. Para um melhor entendimento da reação do pintor Júlio Pomar, em consonância com um protesto de oposição publicado em julho do mesmo ano ${ }^{5}$, que adiante será abordado neste artigo, será necessário conhecer Malta e o seu percurso até 1959.

\section{Quem foi Eduardo Malta?}

3 Nascido na Covilhã a 28 de outubro de 1900, Malta ingressou no curso de Pintura da Escola Superior de Belas Artes do Porto em 1911. Com o indispensável apoio da primeira esposa e alguns amigos ${ }^{6}$, fez um percurso habitual, expondo no Porto e em Lisboa, no Salão da Illustração Portugueza (1922) e na Sociedade Nacional de Belas Artes (SNBA) (1924 e 1927), respetivamente.

4 No final da década de 1920, Malta destacou-se como retratista da sociedade portuguesa e a sua carreira sofreu um importante impulso quando contacta e pinta figuras da aristocracia, altos funcionários de Estado, políticos portugueses e internacionais, destacando-se o General Primo de Rivera (1928). Depois de fixar em pintura o ditador espanhol, e já consagrado como pintor das elites, Malta retrata António de Oliveira Salazar, sendo o único a consegui-lo perante o modelo (1933). Importa referir que este facto constituiu um momento prestigiante e decisivo para a carreira do pintor, assinalando o início de um relacionamento de proximidade com o líder do Estado Novo, que se manteve até ao final da sua carreira ${ }^{7}$. Desta relação resultaram algumas encomendas estatais, como por exemplo para a Primeira Exposição Colonial Portuguesa, em 1934, na qual apresentou vários desenhos e dois painéis de grandes dimensões representando indígenas das colónias portuguesas ${ }^{8}$, ou para a secção Colonial da Exposição do Mundo Português, em 1940, na qual voltou a expor os mesmos retratos de indígenas.

Malta foi também uma presença assídua e premiada em exposições tuteladas pelo Governo, exemplarmente na Exposição Internacional de Paris (1937), com a medalha de ouro para melhor obra decorativa, ou o prémio Columbano, que lhe foi atribuído pelo Secretariado de Propaganda Nacional (SPN) em 1936. Há que salientar que a sua presença se verificava nestas mostras devido, por vezes, à interferência direta do pintor junto de Salazar, como no caso da exposição de Paris, em $1937^{9}$. Até à sua nomeação como diretor do MNAC, expôs regularmente e principalmente sob a tutela do SPN/Secretariado Nacional Informação (SNI), em nome próprio e em exposições coletivas.

6 Estabelecendo desde cedo uma importante rede de contactos, e reconhecido pelos retratos que fez de líderes como Rivera (1928), Salazar (1933) e Getúlio Vargas (1938), Malta movia-se com desembaraço no universo artístico português, sendo benquisto na fação conservadora e detestado pela fação modernista, como será demostrado em seguida. 
7 Impetuoso na defesa dos seus ideais, a polémica em torno da sua imagem adensa-se num ácido episódio ocorrido no seio da SNBA em 1952. Na base deste acontecimento esteve uma crise política motivada por um extremar de posições entre a ultradireita e os sócios não simpatizantes do Regime, ligados ao partido Comunista (Tavares 1999, 318). A celeuma gerou-se entre os concorrentes ao Salão da Primavera, reunidos para a eleição dos respetivos júris, durante o apuramento dos votos pela secção de escultura. Malta afirmara ter visto o escultor José Dias Coelho votar quatro vezes em vez de duas, e foi feita nova verificação de votos, apurando-se dois votos a mais no escultor Armando Mesquita. A questão dos votos ficou resolvida, embora não sanada a calúnia. Como resultado da atitude delatora de índole política por parte de Malta, a Sociedade foi encerrada sob grande controvérsia, culminando na revisão dos estatutos e num controlo mais apertado por parte do Estado ${ }^{10}$.

No que diz respeito à produção pictórica de Malta, esta centrava-se principalmente no retrato, caracterizado por uma abordagem formal conservadora e uma paleta contrastante. Apologista de valores académicos ${ }^{11}$ e declaradamente anti-moderno, a sua obra persegue um carácter atemporal.

Longe de uma ideia de "regresso", impera antes a "ordem" que desde o período entre guerras norteou a produção artística oficial em Regimes autoritários. Não isenta de problemas, a noção Greenbergiana de Kitsch (Greenberg 1989, 3-21) como arte académica, e a fetischização da pintura que Buchloh (1981) encontra nas «figuras de autoridade» ${ }^{12}$ ajudam a criar um enquadramento no qual se insere Malta. Apesar de conformar uma linha de gosto vigente durante o período da ditadura, na crítica da época, seria desacreditado e aludia-se correntemente à sua "pintura anti-rugas», versejando-se anonimamente em cerca de 1955: «Esmalta Eduardo as Damas/M...dina o outro Excelências» (França 1991, 314-315).

\section{A nomeação e o protesto}

10 Ainda que o seu trabalho fosse desvalorizado por alguns dos seus pares, o pintor seria recompensado pelo fiel comportamento delator perante Salazar. No dia da morte de Diogo de Macedo, anterior diretor do MNAC, Malta escreveu ao dirigente, afirmando:

Quem melhor do que eu teria sido Professor de Belas Artes? Ninguém se lembrou de isso. Chegam a pôr gente inferior e das esquerdas em lugares de destaque. [...] 0 Diretor do Museu de Arte Contemporânea, que agora desapareceu, era um homem contrário ao Regime, e só comprou quadros ou valorizou em exposição as obras de comunistas e seus simpatizantes. [...] venho pedir a Vossa Excelência, porque os meus quase 60 anos julgo merecê-lo, este lugar que vagou. Parece-me que ninguém melhor do que eu, [...] poderá dirigir um Museu de Arte Contemporânea, e depois creio, sem vaidade, que esta situação me fará assim um pouco de justiça. [...]. (Malta $1959, \mathrm{~s} / \mathrm{p})$

O pedido foi concedido pelo chefe de Estado e certamente apoiado pela rede de contactos estabelecida ao longo da vida do pintor ${ }^{13}$. A nomeação teve como consequência um protesto requerendo a substituição do pintor, num «documento que recebe mais de duzentas assinaturas de artistas e intelectuais de todas as tendências estéticas e políticas» (França 1991, 486). O documento intitulado Os Artistas Plásticos e o Sr. Malta, foi dirigido a Leite Pinto, ministro da Educação Nacional e manifestava profundas preocupações concernentes a Malta: 
O senhor Malta tem revelado, nas suas atitudes e nos seus escritos, um desconhecimento dos problemas actuais das artes plásticas que o impede de formar juízos críticos responsáveis nas funções de escolha e valoração a que o cargo o obrigará. Ainda pelo seu alheamento do meio artístico, o Senhor Eduardo Malta não se encontra em situação de poder merecer a confiança dos artistas portugueses. Finalmente, estes não lhe reconhecem, como pintor, mérito que justifique, por distinção, a nomeação para o cargo. número de pinturas de Amadeo de Souza Cardoso iniciado pelo antecessor (e que mais tarde ingressaram na coleção da Fundação Calouste Gulbenkian). Durante o mandato de oito anos (1959-1967), adquiriu para o MNAC cerca de 150 obras, conjugando, por vezes, meros acasos e gerindo oportunidades.

16 Apesar de ter afirmado no discurso de tomada de posse que era «necessário antes de tudo, esquecer-nos de nós próprios, da nossa personalidade intrínseca, dos nossos sentimentos e gosto» (A Arte Contemporânea Lembra um Caleidoscópio 1959, 1), as incorporações foram realizadas de acordo com o seu gosto, caracterizado pelo classicismo, centrado na figuração, predominando a paisagem e sobretudo o retrato, privilegiando valores como a técnica aturada, a minúcia, e o mimetismo ao serviço de uma visão idealizada ou atemporalizada da história.

Considerando que a arte contemporânea lhe fazia «lembrar um Caleidoscópio», percebemos o desconforto de Malta perante a arte produzida na época. Não obstante existiram raras exceções em que adquiriu obras de artistas contemporâneos como Bartolomeu Cid dos Santos ou Nikias Skapinakis. Destacam-se estes dois casos específicos por figurarem como assinantes no protesto contra a sua nomeação e por serem artistas opositores do Regime. Apesar das premissas negativas à aquisição, parece evidente que estiveram envolvidas, neste caso, outras questões. Relativamente ao primeiro caso destaque-se que Bartolomeu Cid era neto de Reynaldo dos Santos, amigo próximo de Malta. No segundo, a pintura de Nikias Skapinakis foi adquirida sob pretexto de falsa 
imparcialidade do diretor e contestação da Direcção Geral do Ensino Superior e das Belas Artes (DGESBA) ${ }^{16}$, organismo tutelar do MNAC. O diretor argumentou que a obra em questão tinha, efetivamente, interesse para a coleção, desejando ser imparcial, «tanto nas diversas teorias de arte, como nos artistas escolhidos a figurar neste Museu» ${ }^{17}$. De ressalvar que esta foi uma atitude ímpar, face a maioria das aquisições de obras de artistas contemporâneos serem justificadas pelo diretor sob defesa política ${ }^{18}$. Mas não só. Malta pensava no discurso político de propaganda colonial, adquirindo obras de artistas como José Malhoa para demonstrar que «em Portugal nunca houve descriminação racial» 19. A obra em questão é o retrato de um advogado negro, Adalberto Soares do Amaral Pereira ${ }^{20}$, adquirida precisamente no ano de 1961, que coincidia com o início da Guerra Colonial em África.

No campo da exposição, novamente um diretor que se afirmava imparcial marca o circuito expositivo do MNAC. Durante os oito anos da administração de Malta, foi assumida na exposição permanente a amplitude cronológica da coleção, com início na segunda metade do século XIX e chegando até aos anos 60 do século XX. Foi mantida a organização das salas de forma semelhante à disposição do seu antecessor, Diogo de Macedo: Sala I: Pintores Românticos; Sala II: Columbano; Sala III: Naturalistas; Sala IV: contígua à sala III (onde era apresentado desenho ou pintura); Sala V: Diretores; Sala VI: Modernistas; Sala VII: Contemporâneos; Sala VIII: Escultura e Sala IX: Desenhos; existindo ainda o Jardim de Esculturas.

19 Há que destacar, neste circuito, a criação da sala $\mathrm{V}$ dos diretores ${ }^{21}$, uma novidade criada por Malta e que se inscreveu num tipo de discurso laudatório, onde o diretor em funções já se fazia incluir, em clara atitude de autopromoção e poder. Na continuidade desta temática, a programação de exposições temporárias incluiu apenas uma exposição (1963) dedicada ao primeiro diretor do MNAC, o pintor Carlos Reis. A mostra integrava cerca de 76 peças, organizadas por temas, em agrupamentos de paisagens, cenas de género ou retratos.

\section{Os catálogos}

20 A acompanhar esta exposição temporária, foi publicado o respectivo catálogo, Centenário do Nascimento de Carlos Reis (1963), objeto que lançava as premissas para outra publicação que viria a ser o acontecimento mais polémico da administração de Malta. Para o catálogo do Centenário contribuíram os autores que faziam parte da comissão científica da exposição: Reynaldo dos Santos, Armando de Lucena e Eduardo Malta. Neste contexto, importa salientar a intervenção escrita do último. 0 diretor começou por referir a sua decisão em erguer no jardim do MNAC um marco em homenagem ao pintor e afirma não pretender realizar nenhum estudo sobre Carlos Reis. Não obstante, as linhas seguintes são dedicadas à sua teoria artística racial, sendo tida como referência a obra A Evasão dos Judeus do seu «amigo, talentoso e inquieto» Mário Saa (Malta 1963, XIV).

21 Como afirma a historiadora de arte Raquel Henriques da Silva, o principal mérito atribuído a Carlos Reis neste texto "era ser um genuíno representante da raça ariana» (Silva 1994, 19). Assim se destacava ele de artistas de origem africana (autores de uma «arte rudimentar, caricatural e sintética»), e semita, judeu ou árabe, criadores de uma "arte apartada das realidades físicas do mundo e por essa razão abstracta», expressão artística que para Malta significava «um exotismo mais ou menos snob, ou coisa para dar 
escândalo» (Malta 1963, XV). Com estas afirmações polémicas seria espectável alguma referência na imprensa, porém tal não aconteceu, ou terá sido reprovado pela censura.

O catálogo seguinte, publicado em 1965, foi dedicado à divulgação da coleção do MNAC, com o título Um Século de Pintura e Escultura Portuguesas. Organizado em duas partes, a primeira continha um prefácio questionavelmente assinado por Dulce Malta ${ }^{22}$, seguido do conteúdo gráfico, composto por reproduções de pinturas e esculturas, dispostas cronologicamente.

De modo sucinto a esposa do diretor e conservadora no museu, Dulce Malta, começou por abordar o tema da nomenclatura do MNAC e a sua inadequação face à coleção. Referindo a falta de legitimidade do termo contemporâneo num museu centrado no século XIX, afirmava que, para resolver este problema, deveriam ser retiradas da coleção do MNAC todas as obras dos artistas nascidos nos primeiros anos do século XX, e construir, com o auxílio da Fundação Calouste Gulbenkian (FCG), um novo museu destinado às novas gerações. A manter-se a designação de «contemporâneo», declara, talvez com ironia, que seria necessário fazer crescer constantemente o espaço, «assim como num comboio ao qual se possam ajuntar novas carruagens». Sem ligação direta com o início do texto, a conservadora parte depois para a crítica à exposição de arte francesa promovida pela FCG em 1965 e, considerando a seleção artística, escreve em tom de ataque: «o que menos se via era artistas de pura ascendência francesa» (Malta 1965, 11). O discurso, que já era pouco erudito, tomou posteriormente contornos semelhantes «a proclamações e actos alemães, mas de trinta anos antes» (cit. por Silva 2002, 92). Relativamente à mesma exposição, Dulce Malta afirmava:

[que] faltavam ali os autênticos pintores de origem gaulesa, aqueles que há cinquenta anos eram os melhores, os mais queridos e bem pagos", e que Paris tinha sido "invadida por verdadeiras legiões de semitas, sobretudo israelitas [...] raça, que não tinha verdadeira ascendência artística, plástica sobretudo, como os descendentes dos godos, suevos gregos ou romanos. (Malta 1965, 11)

Esta proclamação antissemita é reforçada pela xenofobia transmitida em afirmações referentes à invasão e internacionalização destes ideais. Continuando, são nomeadas personalidades nacionais e internacionais, à maneira de Mário Saa. Cite-se uma passagem elucidativa:

[[圆] infiltraram-se, inteligentemente e com pés de lã, nos Museus e organismos oficiais para assuntos de arte, e dentro de poucos anos vemos nas direcções acompanhados por Conservadores, homens da mesma origem. [...] Paris hoje é uma cidade mais semita que gaulesa. Onde encontramos aqueles homens fortes, decididos e de grandes e vistosos bigodes loiros? Vê-se mais gente pálida, de nariz em forma de seis e de pés a direito por modelar. Pissaro, Picasso, filho de judia italiana, Modigliani, Matisse, Rouaul, Chagall, Friez, Leger, Pascin, Marquet, Kisling ${ }^{23}$ e tantos mais, e até Vieira da Silva, de raça safardim, creio que da verdadeira aristocracia judaica em Portugal. (Malta 1965, 13)

Ainda são tecidos reparos aos críticos de arte que «quase sempre são homens falhados em feitos literários ou poéticos [...] incapazes de uma visão clara resultado do artifício cego que vem da política, da raça e muitas vezes de estranhos conluios e até de seitas» (Malta 1965, 15).

Apesar de o prefácio estar assinado por Dulce Malta, parece possível questionar a autoria do texto, que sem grande espanto poderá ter sido redigido por Eduardo Malta. Esta hipótese é avançada e sustentada pela proximidade dos temas abordados na correspondência interna do $\mathrm{MNAC}^{24}$, na qual se encontram diversos ofícios de anos 
anteriores referentes aos temas da exposição promovida pela FCG, sobre a mudança de nomenclatura do MNAC, ou sobre a possibilidade de apoio da mesma Fundação para a criação de um novo museu, sendo utilizadas inclusivamente as mesmas expressões.

Contrariamente ao catálogo da exposição de Carlos Reis, Um Século de Pintura e Escultura Portuguesas, provocou reações críticas. Publicado em março de $1966^{25}$, a receção negativa fez-se sentir de imediato na imprensa, sendo o catálogo apelidado de «autêntico molho de brócolos» (Rego 1966, 17) face à seleção e organização de artistas mediante as suas datas de nascimento. A própria legitimidade e competência da autora foi contestada em diferentes jornais. Raul Rego questionava: «Não se pode todavia deixar de perguntar, a que propósito foi esse prefácio confiado a D. Dulce Malta, sem sabermos da categoria intelectual, académica literária ou oficial que a recomende para o efeito» (Rego 1966, 17); e Sellés Paes concluía: «Não teria prestado melhor serviço à cultura nacional entregando o texto a pessoa culturalmente responsável?», isto porque «dificilmente lemos texto oficial com tamanha pobreza de linguagem, já que sobre as ideias expostas, sem fundamento nem preparação, se manifestou o Ministério que custeou o volume e autorizou a sua venda» (Paes 1966, 8).

Devido ao conteúdo reacionário e racista, o prefácio constituiu «uma situação inédita, mesmo no contexto do salazarismo» (Silva 2002, 92), gerando uma resposta por parte do SNI, que redigiu nas suas Nótulas sobre Letras e Artes, uma crítica ao conteúdo expresso no catálogo, salvaguardando o posicionamento contrário relativamente à organização metodológica:

Foi recentemente posto em recente livro, profusamente ilustrado, e na imprensa, com sentido laudatório e de total acerto, o arrumo dos criadores e oficiais do mesmo ofício em disciplina cronológica ou seja arrumados, agrupados dentro de limites de um século. Assim um museu englobaria os artistas nascidos entre $1800 \mathrm{e}$ 1900; outro os nascidos a partir de 1901 e por aí adiante. Perigoso plano e errada concepção da Arte não vista neste caso como fruto de espírito mas como acidente da vida do indivíduo tal qual o nascimento, o casamento, a separação de pessoas e bens, a morte. Os museus que são, devem, ser órgãos vivos, livros abertos de cultura e de informação têm que ser agrupados por termos culturais que nada têm a ver com os anos do autor do testemunho ou manifestação. (SNI 1966, s/p)

Embora não se refira o essencial - o teor racista da reflexão sobre a arte contemporânea, a obra foi retirada de circulação "por determinação superior» ("Ofício n.. 35" 1970, s/p). Materialização de um pensamento redutor e anti-moderno, este catálogo não cumpria a função como veículo de divulgação das coleções do museu, transmitindo uma mensagem facciosa, racista e reacionária. A este pensamento, juntava-se ainda a conduta do diretor, que conduzia o MNAC a um maior fechamento ao público. A situação agravou-se a partir de $1963^{26}$ com um ofício da DGESBA, que alertava para os empréstimos e as visitas desnecessárias às reservas dos museus. Legitimando as intenções do diretor na não divulgação da coleção do MNAC, este podia assim negar com mais facilidade o acesso e estudo da coleção, como exemplificado neste excerto:

Este Museu está ao lado do Governo Civil de Lisboa, dum paiol de pólvora e algumas paredes divisórias são feitas de estafe, não sendo aconselhável portanto deixar ir às arrecadações pessoas que pelas suas atitudes públicas anti-nacionais não merecem confiança. José-Augusto França como crítico de arte apenas valoriza os artistas pelas suas filiações políticas. Este Museu tem actualmente a serviço apenas três contínuos que são insuficientes para guardar as salas de exposição não podendo esta Direcção dispensar qualquer deles para acompanhar um estranho que pretende estudar (!) nas arrecadações que são salas mal iluminadas onde os quadros estão muito juntos e portanto dificilmente manejáveis. [...] Além disso o $1^{\circ}$ catálogo deste 
museu, que apenas espera uma resposta de Vossa Excelência o senhor Ministro para sair do prelo, ficaria desvalorizado na venda que possa vir a ter, com outras publicações. (Malta 1965, s/p)

\section{com o Regime, «voltou-se para dentro» (Ramos, Sousa e Monteiro 2009, 691),} contrariando a atividade da direção anterior, que organizou exposições itinerantes, divulgando as coleções a nível nacional. Após a morte de Malta, em 1967, o fechamento do MNAC permaneceu com a administração seguinte de Dulce Malta, a primeira diretora mulher, não-artista. Em lógica de sucessão, a viúva deu continuidade, durante três anos, ao trabalho desenvolvido pelo marido ${ }^{27}$.

A mudança de regime político que o 25 de Abril de 1974 assinalou, também não se fez sentir de imediato no papel do MNAC, que dirigido por Maria de Lourdes Bártholo, entre 1970 e $1987^{28}$, se manteve pouco relevante no panorama museológico nacional da arte contemporânea. Esta condição era coadjuvada por alternativas institucionais mais eficazes, como a FCG, que apoiava os artistas através de bolsas de estudo, assim como a proliferação de novas galerias e outros espaços expositivos ${ }^{29}$, resultado de um mercado de arte emergente. A modernização do sistema museológico português e a aplicação de práticas atualizadas também «não constituíram tarefa fácil» (Pimentel 2005, 153) durante as décadas de 1970 e 1980, verificando-se alterações significativas apenas no início de década de 1990. O MNAC é, enfim, recuperado nesse período. Encerrado em 1987, reabriu em 1994 sob a direção de Raquel Henriques da Silva, com um programa «fundamentado nas máximas potencialidades das suas coleções, de exibir as artes plásticas portuguesas de 1850-1950, numa atividade voltada para a memória das heranças, mas aberta ao futuro, através de exposições temporárias» (Silva 2002, 97).

\section{Notas finais}

Para concluir, parece evidente que Malta foi uma figura-chave no campo artístico do Estado Novo, particularmente por ter sido um dos raros artistas estimados por Salazar. Ambos partilhavam gostos e opiniões ${ }^{30}$ e os seus modos de atuação relacionavam a política instituída com o programa artístico. Malta assumiu com especial crueza e obediência as orientações do Regime, que no final da década de 1950 e durante a década de 1960 estavam alicerçadas num discurso cultural e estético que se afastou do dito “período áureo" de António Ferro.

Embora Malta dirigisse o MNAC durante uma fase de recuperação museológica na Europa e de relativa mutação no panorama nacional ${ }^{31}$, o Estado Novo manteve os desempenhos característicos de um Governo totalitário: o continuado uso propagandístico dos museus, a sujeição das peças museológicas a usos políticos e ideológicos e o recurso intenso a exposições temporárias eivadas de propaganda ideológica e de fins doutrinadores (Lira $2001,2)$. Neste paradigma, o MNAC serviu como espaço para a reafirmação de controlo e poder do Estado na área da arte contemporânea. A escolha de Malta para o cargo de 
director revelou-se inadequada e a sua ação, fornecem, portanto, uma imagem expressiva das últimas décadas de vigência do Estado Novo e respetivas práticas culturais.

\section{BIBLIOGRAFIA}

“A Arte Contemporânea Lembra um Caleidoscópio”. 1959. Diário de Notícias. 14 de Maio, pp. 1-6.

“Ofício n.․ 35”. 1970. Arquivo Museu Nacional Arte Contemporânea (MNAC), Livro de Ofícios enviados 1968-70, n.․ 35, 16/7/1970.

“Ofício n. 5625”. 1963. Arquivo Museu Nacional Arte Contemporânea (MNAC), Livro de Ofícios enviados n.. $27,10 / 05 / 63$.

Buchloh, Benjamin. 1981. "Figures of Authority, Ciphers of Regression: Notes on the Return of Representation in European Painting." October 16, Art World Follies (Spring): 39-68.

Duro, Rita. 2012. "Eduardo Malta, Director do Museu Nacional de Arte Contemporânea." Dissertação de mestrado em Museologia, Faculdade de Ciências Sociais e Humanas da Universidade Nova de Lisboa.

França, José-Augusto. 1991. A Arte em Portugal no Século XX (1911-1961). Lisboa: Bertrand.

França, José-Augusto. 2011. Entrevista conduzida por Rita Duro em novembro de 2011, Lisboa. Material não publicado.

Greenberg, Clement. 1989. “Avant-Garde and Kitsch.” In Art and Culture: Critical Essays, 3-21. Boston: Beacon Press.

Lira, Sérgio. 2001. "O Estado Novo de 1945 a 1974: A Ditadura Nacionalista e a Prática Legislativa Relativa aos Museus: Cristalização e Mudança.” In Seminário sobre Ditaduras Europeias. Porto: Universidade Fernando Pessoa.

Malta, Dulce. 1965. Um Século de Pintura e Escultura Portuguesas. Lisboa: Museu Nacional de Arte Contemporânea.

Malta, Eduardo, Reynaldo Santos, e Armando Lucena. 1963. Centenário do Nascimento de Carlos Reis. Lisboa: Museu Nacional de Arte Contemporânea.

Malta, Eduardo. 1936. "Carta de Eduardo Malta a Salazar." Arquivo Nacional da Torre do Tombo (ANTT), Fundo AOS/CP-167, carta de 12/10/1936.

Malta, Eduardo. 1938. Retratos e Retratados. Rio de Janeiro: A Noite.

Malta, Eduardo. 1948. A Arte de Ontem e de Hoje. Lisboa: R.E.S.M.

Malta, Eduardo. 1952. Vários Motivos de Arte. Lisboa: Ed. Portugália.

Malta, Eduardo. 1959. "Carta de Eduardo Malta a Salazar." Arquivo Nacional da Torre do Tombo (ANTT), Fundo AOS/CP-167, carta de 19/2/1959.

Malta, Eduardo. 1961b. “Ofício 87.” Arquivo Museu Nacional Arte Contemporânea (MNAC), Livro de Ofícios enviados, n. 26 . 
Malta, Eduardo. 1961c. “Ofício n. 95.” Arquivo Museu Nacional Arte Contemporânea (MNAC), Livro de Ofícios enviados, n.․ 26, 11/10/1961.

Malta, Eduardo. 1963. “Ofício n.ำ28.” Arquivo Museu Nacional Arte Contemporânea (MNAC), Livro de Ofícios enviados, n. ${ }^{2} 28,28 / 3 / 63$.

Malta, Eduardo. 1965. “Ofício n.․⒉” Arquivo Museu Nacional Arte Contemporânea (MNAC), Livro de Ofícios enviados, n.. 30, 31/3/65.

Malta, Eduardo. 1966. “Ofício” Arquivo Museu Nacional Arte Contemporânea (MNAC), Livro de Ofícios enviados, n. 31, 11/03/1966.

Malta, Educado. 1961a. “Ofício 86." Arquivo Museu Nacional Arte Contemporânea (MNAC), Livro de Ofícios enviados, n. 26, 18/09/61.

Os Artistas Plásticos e o Sr. Malta: Protesto Contra Nomeação de Eduardo Malta para Diretor do MNAC. 1959. [s.l.]: [s.n.]. Panfleto pertencente ao espólio de José-Augusto França.Paes, Sellés. 1966. “A Bibliografia de Arte Publicada este Ano em Portugal." Diário da Manhã, 28 de Abril, pp. 7-8.

Pimentel, Cristina. 2005. O Sistema Museológico Português (1833-1991) em Direcção a um Novo Modelo Teórico para o seu Estudo. Lisboa: Fundação Calouste Gulbenkian.

Ramos, Rui, Bernardo Vasconcelos Sousa, e Nuno Gonçalo Monteiro. 2009. História de Portugal. Lisboa: Esfera dos livros.

Rego, Raul. 1966. “Um Século de Pintura e Escultura Portuguesas.” Diário de Lisboa, 20 de Abril, p. 17.

Salazar, António de Oliveira. 1963. "Salazar em Correspondência com Eduardo Malta." Arquivo Nacional da Torre do Tombo (ANTT), Fundo AOS/CP-167, carta de 2/2/63.

Silva, Raquel Henriques da. 1994. Museu do Chiado: Arte Portuguesa 1850-1950. Lisboa: Instituto Português de Museus.

Silva, Raquel Henriques da. 2002. “Os Museus: História e Prospectiva.” In Panorama da Cultura Portuguesa no Século XX, AA.VV., 65-107. Porto: Edições Afrontamento e Fundação Serralves.

Silveira, Maria de Aires. 2015. Imagens de Figueiró. N. 2. Figueiró dos Vinhos: Figueirotipo.

Skapinakis, Nikias, e Fernando Azevedo. 1987. Algumas Perguntas a Nikias Skapinakis. Lisboa: Imprensa Nacional-Casa da Moeda.

SNI. 1966. "Nótulas sobre Letras e Artes." II Série, n. 228. In Informações/Secretariado Nacional de Informação (SNI), Biblioteca Nacional. 27/5/66.

Tavares, Cristina de Sousa. 1999. "Naturalismo e Naturalismos na Pintura Portuguesa do Séc. XX e a Sociedade Nacional de Belas-Artes." Dissertação de doutoramento em História da Arte, Faculdade de Ciências Sociais e Humanas da Universidade Nova de Lisboa.

Valdemar, António. 2002. “Herança de Eduardo Malta.” Diário de Notícias, 25 de Julho, p. 36.

\section{NOTAS}

1. Este artigo resulta da investigação realizada no âmbito da dissertação de mestrado em Museologia intitulada Eduardo Malta, director do Museu Nacional de Arte Contemporânea (Duro 2012).

2. Nesta década existia uma cultura museológica materializada na organização de exposições que serviam o discurso estatal, e na composição de coleções destinadas a veicular a representatividade portuguesa tradicional (Lira 2001, 2). No entanto, surgem indícios de inovação 
protagonizada por indivíduos das esferas museológicas pública e privada como, por exemplo, João Couto, diretor do Museu Nacional de Arte Antiga, e José Azeredo de Perdigão, presidente da Fundação Calouste Gulbenkian (FCG).

3. Nomeia-se exemplarmente a FCG, criada em 1956, cuja ação detinha um forte sentido de caráter público.

4. Júlio Pomar em artigo não publicado consultado no espólio Diogo de Macedo na Fundação Calouste Gulbenkian. O espólio Diogo de Macedo contém diversos artigos recolhidos por Eva Arruda de Macedo após a morte do escultor. Este artigo terá sido censurado, porque o mesmo é referido em entrevista a José-Augusto França (2011) e não foi encontrado em nenhuma publicação da época.

5. Júlio Pomar também figurava na lista dos cerca de 200 assinantes deste protesto, datado de 1 de julho de 1959.

6. Destacam-se entre estes amigos os escritores Augusto Santa-Rita e Teixeira de Pascoais. A esposa, Maria de Lourdes Alarcão Albuquerque, proveniente de uma família abastada, proporcionou-lhe o conforto financeiro necessário.

7. Facto comprovado pela frequente correspondência existente no Arquivo Nacional da Torre do Tombo e no Arquivo Histórico da Santa Casa da Misericórdia.

8. Estes dois grandes painéis retratando indígenas das colónias de Timor e África seriam os painéis laterais de um tríptico iniciado por Malta. No painel central figuravam Henrique Galvão, seu parente e diretor da exposição, Salazar, Presidente do Conselho, Armindo Monteiro, Ministro das Colónias, e o Presidente da República, Óscar Carmona. Contudo, o painel central nunca chegou a ser concluído. Os painéis laterais que figuraram nas exposições pertencem atualmente à Fundação Bissaya Barreto.

9. Exposição em que o pintor não constava na lista inicial de artistas seleccionados, mas que após carta escrita a Salazar, participaria como decorador do Pavilhão de Portugal: «[...] Esta carta não é só uma defesa aos meus interesses, mas defendo outros artistas que, se as coisas não mudarem, ficarão lesados. [...] Venho pedir a V. Ex.. justiça, pedir-lhe que a escolha dos decoradores do Pavilhão de Portugal seja feita por concurso. Tem defeitos esse processo? Tem muitos. Mas sempre será melhor essa escolha de artistas do que esta, nascida das amizades pessoais e do mau gosto» (Malta 1936, s/p).

10. Para mais informações sobre este episódio consultar Tavares (1999).

11. Como referência para esta ideia apontam-se as suas influências e preferências artísticas centradas maioritariamente nos mestres do séc. XV e XVI, nomeadamente Hans Holbein, Jan Van Eyck, Hugo Van Der Goes, Van der Weyden, Hans Memling, Rafael, Albrecht Dürer ou Leonardo da Vinci. Para o século XIX apontam-se pintores como David, Edgar Degas, Jean-Baptiste-Camille Corot ou Pierre Puvis de Chavannes (Malta 1938).

12. Ainda que a pintura de Malta não permita falar num regresso ou regressão à ordem, parece evidente que se encontra comprometida na criação de um clima de autoridade (Buchloh 1981, 39-68).

13. Nesta rede destacam-se personalidades decisivas para este desfecho, e que eram amigos próximos tanto de Salazar, como de Malta, nomeadamente Reynaldo dos Santos, médico do estadista e João de Almeida, diretor da Direção Geral do Ensino Superior e das Belas Artes.

14. Informação transmitida por José-Augusto França em entrevista realizada em Novembro de 2011.

15. O documento que circulou publicamente é datado sensivelmente de março de 1960. O primeiro foi apresentado ao ministro oito meses antes. Ao ter passado este longo período sem resposta, alguns dos signatários consideraram-se desligados do compromisso, possivelmente com o receio de represálias do Governo.

16. O questionamento da DGESBA confirma o controlo estatal sobre as coleções dos museus ao nível autoral, sendo Nikias Skapinakis um dos artistas opositores ao Regime desde os anos de 
1940. Nikias expunha com outros artistas nas Exposições Gerais de Artes Plásticas, que desde 1946 aglutinavam a oposição dos artistas ao Governo. Excerto de texto originalmente publicado em Algumas Perguntas a Nikias Skapinakis (1987).

17. Malta defende a sua escolha: «Eu sei que o artista em questão, que não conheço nem de vista, é meu inimigo político e artístico. Não me interessa. Entrei na Galeria do "Diário de Notícias", ao Chiado, e das obras expostas esta pareceu-me a mais original, (menos parecido com obras estrangeiras) e como o artista não estava ainda representado no Museu, resolvi propor o quadro a V. Ex ${ }^{\mathrm{a}}$ para ser adquirido» (Malta 1961a, s/p).

18. Destaca-se a justificação de outra aquisição em que o diretor é contraditório na argumentação e acentua as tendências políticas dos artistas: «[...] as razões da proposta. A desta é a seguinte: Ruy Preto Pacheco, não só pelo valor como pintor e grandes faculdades de jornalista deveria de há muito estar representado neste museu. Só o não está porque a antecedente direção preocupava-se mais com a filiação ou tendências políticas dos artistas do que propriamente o seu valor intrínseco. O Ruy Preto é das direitas, tanto em arte como em política, e por essa razão não tinha direito a figurar neste museu. Dalguns artistas da situação retiraram os quadros (eu por exemplo tinha três expostos no tempo de direção do pintor Sousa Lopes, passei a ter um e mal colocado) e o Portela Júnior, como faz parte da União Nacional, não só retiraram todos os seus quadros, como despregaram as telas das grades, que enrolaram e deitaram fora as molduras... Enquanto eu for diretor deste museu a política não contará nada em favor ou desfavor dos valores em arte» (Malta 1961b, s/p).

19. Malta defende a sua proposta para aquisição da obra, afirmando que esta obra foi assinalada pelo antigo ministro, e que as negociações já teriam sido iniciadas (Malta 1961c).

20. Adalberto Soares do Amaral Pereira era advogado e funcionário da Conservatória do Registo Predial em Figueiró dos Vinhos (Silveira 2015, 3).

21. Na Sala dos Diretores, Malta reúne 18 peças dos pintores Carlos Reis e Sousa Lopes, aumentando a representação de Diogo de Macedo para sete peças, solicitando o depósito de dois bustos à viúva. Malta fez-se representar através de cinco pinturas da sua autoria.

22. Era esposa de Malta e conservadora-ajudante no MNAC. O cargo foi publicado em Diário de

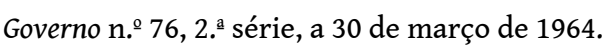

23. Artista que Eduardo Malta chegou a retratar em 1940, quando este estava de passagem por Portugal, refugiado da Segunda Guerra Mundial, dirigindo-se para os Estados Unidos. O retrato pertence ao Museu José Malhoa. Para informação mais detalhada sobre retrato consultar: http:// www.matriznet.imc-ip.pt/MatrizNet/objectos/objectosConsultar.aspx?IdReg=41797.

24. Foi consultada toda a correspondência interna do MNAC, livros de ofícios enviados e recebidos no período de 1959 a 1967. Além desta fonte oficiosa, os livros publicados por Eduardo Malta ao longo da sua carreira permitem atestar o mesmo pensamento, nomeadamente: Retratos e Retratados de 1938, A Arte de Ontem e de Hoje de 1948 e Vários Motivos de Arte de 1952.

25. Corroborando a data desta afirmação, apresenta-se um ofício em que Malta agradece a felicitação da DGESBA: «Agradeço muito a Vossa Excelência ter-me felicitado pelo $1^{\circ}$ volume de Obras de Arte, publicado neste Museu, com gastos mínimos. Minha mulher, que tanto me ajuda, agradece também muito sensibilizada. Mando juntamente com estas linhas 20 exemplares para esse Ministério» (Malta 1966, s/p).

26. Ano em que é promulgada uma ordem de serviço pela DGESBA, limitando a cedência de objetos existentes nos museus. $O$ empréstimo de obras passou a ser mais condicionado devido à sua pertinência, avaliada pela DGESBA, e o acesso de pessoas estranhas às reservas dos museus foi proibida. Simultaneamente, os diretores foram proibidos de facultar qualquer informação que propicie o pedido de cedência de objectos ("Ofício n.․ 5625" 1963, s/p).

27. Após a morte de Eduardo Malta, a conservadora assumiu interinamente a direção do MNAC em 1967. Nesse ano a diretora desejava organizar uma exposição temporária em homenagem ao 
falecido marido, porém nunca chegou a ser concretizada, não havendo acontecimentos de destaque durante os três anos da sua administração.

28. Quando Maria de Lourdes Bártolo tomou posse no MNAC procedeu logo de início a obras de melhoramento dos acervos do museu e fez um levantamento fotográfico de todos os espaços. No entanto, estes vão deteriorando-se ao longo dos anos e o MNAC permaneceu em funcionamento até 1987 , data em que foi obrigado a encerrar. Durante a sua administração assinala-se uma relativa abertura do acervo a propostas contemporâneas, sendo incorporadas algumas obras de artistas de referência como Jorge Vieira e Paula Rego e destacam-se como iniciativas de destaque as exposições temporárias: A Criança nas Colecções do Museu, em 1979, Meio Século de Arte Portuguesa (1900-1950), em 1980, Miguel Ângelo Lupi: Evocação no Centenário da sua Morte nas Colecções do MNAC e Malhoa nas Colecções do Museu Nacional de Arte Contemporânea: Evocação do Cinquentenário da sua Morte, ambas em 1983.

29. No final da década de 1960 e ao longo da década seguinte inauguram, no Porto, a Zen (1970) e o Módulo-Centro Difusor de Arte (1975); em Lisboa, a Buchholz (a partir de 1965, na Rua Duque de Palmela), a Dinastia (1968), a Judite da Cruz, a S. Mamede (1969), a Quadrum (1973) e o segundo espaço do Módulo (1979); e, em Óbidos, a Ogiva (1970).

30. Confirmando o protecionismo de Salazar e a partilha de gostos, cite-se uma frase do chefe de Estado relativamente à arte contemporânea, sobre a qual admite que ambos seriam «de outro mundo, que em todo o caso, produzia coisas mais belas» (Salazar 1963, s/p).

31. A título de exemplo desta mutação museológica em Portugal, nomeie-se em 1965: o Estado promulgou o novo Regulamento Geral dos Museus de Arte, História e Arqueologia que, entre as várias medidas inovadoras, transformou em Curso o anterior estágio de conservadores, de modo a formar profissionais mais preparados e capazes; a participação de Portugal no Conselho Internacional de Museus (ICOM); a criação da Associação Portuguesa de Museologia (APOM); e a própria definição de conceito de museu conheceu nesta altura uma autêntica revolução, passando o museu a ser um organismo cultural ao serviço da comunidade, com uma missão científica, artística, educativa e social (Lira 2001,2).

\section{RESUMOS}

Eduardo Malta (1900-1967) foi um controverso diretor do Museu Nacional de Arte Contemporânea (MNAC) entre 1959 e 1967. Este período foi considerado pela historiografia portuguesa como um dos mais negros na história desta instituição museológica, constituindo um "caso de estudo" na história da museologia portuguesa. Ao longo da sua carreira artística, Eduardo Malta estabeleceu uma valiosa rede de contactos no regime do Estado Novo e foi um artista protegido por António de Oliveira Salazar. A sua nomeação como diretor do MNAC representou um exercício de poder por parte do Estado Novo, contrariando a opinião pública das esferas artística e intelectual, que reagiram através de um protesto com mais de 200 subscritores. Neste artigo pretende-se apresentar a figura do pintor e analisar a sua administração no MNAC, através de pontuais episódios centrados nas aquisições, exposições permanente e temporária, catálogos publicados e na comunicação com os públicos. Em simultâneo, reflete-se sobre a sua inadequação ao cargo, em parte representativa do discurso museológico do Regime à época.

Eduardo Malta (1900-1967) was a controversial diretor of the National Museum of Contemporary Art between 1959 and 1967. This period was considered by the Portuguese historiography as one 
of the darkest in the history of this institution, constituting a case study in the context of Portuguese museum studies. Eduardo Malta established throughout his career a valuable network of contacts in the Estado Novo Regime and was an artist protected by António de Oliveira Salazar. His appointment as diretor of MNAC represented an exercise of power by the state, going against the public opinion from artistic and intellectual spheres that reacted with a protest signed by more than two hundred people. This article aims to introduce the painter and then analyse his administration at MNAC, pinpointing specific episodes on the acquisitions, the permanent and temporary exhibitions, the published catalogues and the communication with the public. Simultaneously, we will reflect about the diretor's inadequacy, partially representative of the museum discourse performed by the Regime of that period.

\section{ÍNDICE}

Keywords: Eduardo Malta, Museu Nacional de Arte Contemporânea, Dulce Malta, Portuguese dictatorship

Palavras-chave: Eduardo Malta, Museu Nacional de Arte Contemporânea, Dulce Malta, Estado Novo

\section{AUTOR}

\section{RITA DURO}

Licenciada em História da Arte pela Faculdade de Ciências Sociais e Humanas da Universidade Nova de Lisboa (2009); mestre em Museologia pela mesma faculdade, com uma dissertação subordinada ao tema Eduardo Malta - Diretor do Museu Nacional de Arte Contemporânea (1959-1967) (2012). Tem colaborado como mediadora cultural em diversas instituições, nomeadamente: Museu Nacional de Arte Contemporânea - Museu do Chiado (2009-2015) Palácio Nacional da Ajuda (2013), Museu Nacional de Arte Antiga (2014), Galeria Millennium (2013-2015), entre outras. A par desta atividade exerce trabalhos pontais de investigação para várias instituições. Atualmente integra a equipa das Galerias Municipais de Lisboa (EGEAC), exercendo funções de assistente técnica e serviço educativo. aritaduro@gmail.com 